\title{
Malaysia Airlines Flight MH370: Water Entry of an Airliner
}

\author{
Goong Chen, Cong Gu, Philip J. Morris, Eric G. Paterson, Alexey Sergeev, \\ Yi-Ching Wang, and Tomasz Wierzbicki
}

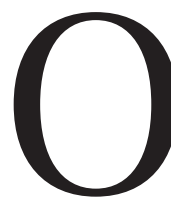

N MARCH 8, 2014 Malaysia Airlines Flight MH370 disappeared less than an hour after take-off on a flight from Kuala Lumpur to Beijing. The Boeing 777-200ER carried twelve crew members and 227 passengers. On March 24 the Malaysian Prime Minister announced that "It is therefore with deep sadness and regret that I must inform you that ...Flight MH370 ended in the Southern Indian Ocean." Though the exact fate of Flight MH370 remains undetermined, the available evidence indicates a crash into the ocean. However, disturbing as this is, not all emergency water landings, referred to as "ditching" when they are controlled, end in tragedy. In the "Miracle on the Hudson," on January 15, 2009, Capt. Chelsey B. "Sully" Sullenberger and his crew successfully ditched US Airways Flight 1549, an Airbus A320200, in the Hudson River after a loss of power due to a bird strike on take-off from La Guardia Airport. There was no loss of life.

Figure 1 and the video animation referenced on the second page of this article show our "representation" of a commercial airliner, a Boeing 777

Goong Chen is professor of mathematics at Texas A\&M University (TAMU) and Texas A\&M University at Qatar (TAMUQ). He is also a member of the Institute for Quantum Science and Engineering at TAMU. His email address is gchen@math . tamu . edu.

Cong $\mathrm{Gu}$ is a PhD student in the mathematics department of TAMU. His email address is gucong@math. tamu. edu.

Philip J. Morris is Boeing/AD Welliver Professor of Aerospace Engineering at The Pennsylvania State University. His email address is pjm@psu. edu.

DOI: http://dx.doi.org/10.1090/noti1236 model, plunging into the ocean. (See our commentary in Box 1 in section "The Water Entry Problem Revisited".) Such simulations can help to understand the physical mechanisms at work and also to improve passenger safety. But these are highly challenging simulations that require the cooperation of engineers, mathematicians and computational scientists. Any scientific investigation of the mishap, apart from human factors of foul play and conspiracy, must consider factors of an engineering nature, such as machine and instrumentation breakdown, midair explosion, weather, navigation, etc. But this should not prevent mathematicians' curiosity-and our fascination with airplanes since childhood-from entering the fray to add and contribute something valuable regarding this investigation and recovery effort. The fact is, mathematics is closely intertwined with engineering and is not detached from the "real world" as some people may think. The statement made by the Malaysian Prime Minister that Flight MH370 "ended" in the Southern Indian Ocean was based on the assessment by the British company

Eric G. Paterson is Rolls Royce Commonwealth Professor of Marine Propulsion and department head of Aerospace and Ocean Engineering at Virginia Tech. His email address is egp@vt. edu.

Alexey Sergeev is postdoctoral fellow at the Qatar Environment and Energy Research Institute in Doha, Qatar. His email address is asergeev@asergeev.com.

Yi-Ching Wang is a PhD student in the mathematics department of TAMU. Her email address is ycwang@ math. tamu.edu.

Tomasz Wierzbicki is professor of applied mechanics and Director of Impact and Crashworthiness Laboratory at MIT. His email address is wi erz@mit. edu. 


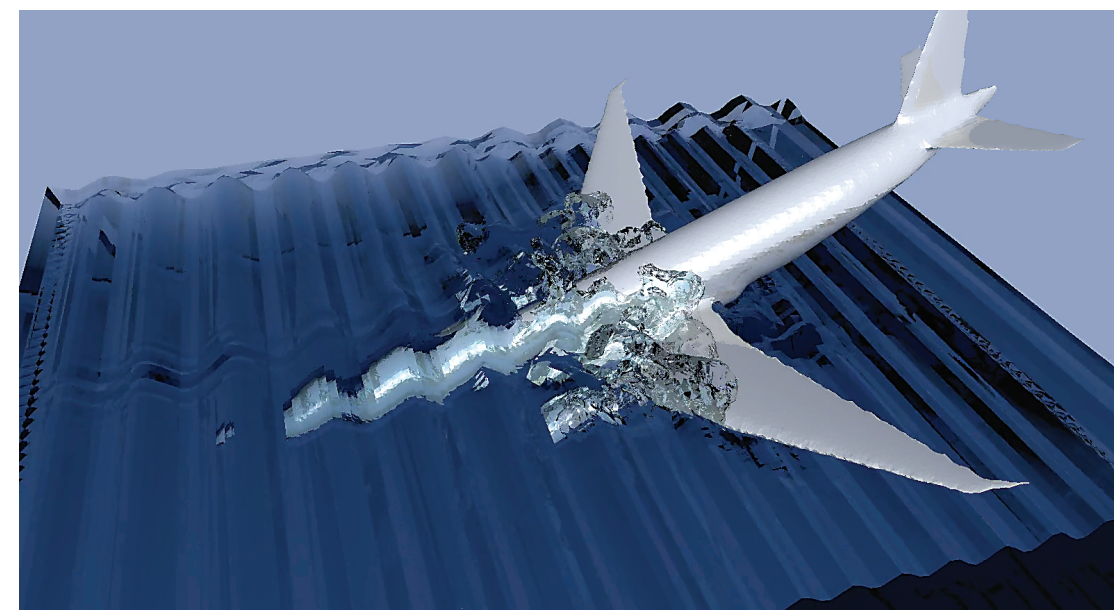

Figure 1. The aircraft is a Boeing 777 model flying into the ocean at the speed of $70 \mathrm{~m} / \mathrm{sec}$, with pitch angle $=-20^{\circ}$, at time $t=0.36 \mathrm{sec}$. A volume-of-fluid (VOF) scheme in OpenFOAM ([ope]) is used to simulate the two-phase flow for the fluid-aircraft body interaction. Please also use the link https://www. dropbox.com/s/pbjhrovlqrqiizm/smooth-cin40.avi to view the corresponding video animation of the dynamic motion.

Inmarsat. An article articulating how the radar signal backtracking made by Inmarsat works was published in SIAM News in [Zwe14], where John Zweck of the Math Department of the University of Texas-Dallas argued in support of Inmarsat by using the Doppler frequency shift, time and locations of ping, trigonometry and other mathematical methods, and MATLAB ${ }^{\circledR}$ software. Nevertheless, Inmarsat's radar tracking methodology and data analysis have not yet convinced everybody that they are ironclad; see some counter arguments by David Finkleman in [Fin14], for example. (Dr. Finkleman is Director of Studies and Analysis, and Senior Scientist, North American Aerospace Defense Command and US Space Command, at Peterson Air Force Base, Colorado.)

We discuss this air incident from a mathematical as well as an interdisciplinary perspective. We show how computational mathematics and mechanics can help us understand the physical nature of an aircraft emergency water landing, how to model and compute it, and how this knowledge is helping safe civil aviation and other aerospace-related undertakings. This kind of problems has become quite typical for the work of a mathematician as part of an interdisciplinary team in industry or government labs.

The problem under consideration is dynamic in nature and is best viewed with the aid of video animation. We encourage the reader to see such animations through the various URLs provided in the article by pasting and clicking them, using the online version of the paper in the Notices [not].

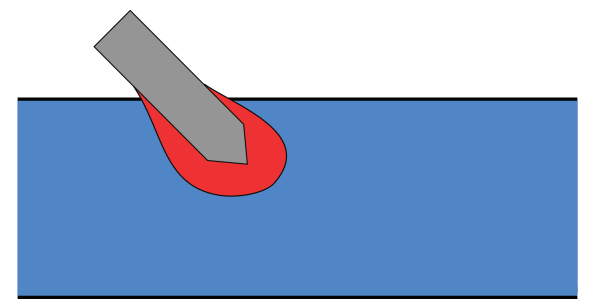

Figure 2. Von Karman's idea of "added mass" for the water entry problem, which is an idealization and simplification. Here the red region represents "added mass." This is the mass moving together with the mass of the wedge projectile. The portion of the (red) added mass lying above the still water surface is called the "pile up."

\section{The Water Entry Problem Revisited}

The water entry problem is a classical problem in applied mathematics and fluid dynamics. It considers the dynamic motion of an object upon its entry into the water. The problem was motivated by several applications: the landing of a hydroplane, the entry into water of a rocket or the Apollo module returning from space, and the ditching or crashing of aircraft.

A major contribution to this field was made by the celebrated applied mathematician and fluid dynamicist Theodore von Karman (1881-1963). He developed the idea of "added mass" (a mass of the fluid that is co-moving with the body) to study the problem [vK29]; see Figure 2. Von Karman inferred that the impact force on the body is related to the instantaneous change of total momentum of the body with its own mass but with an extra 


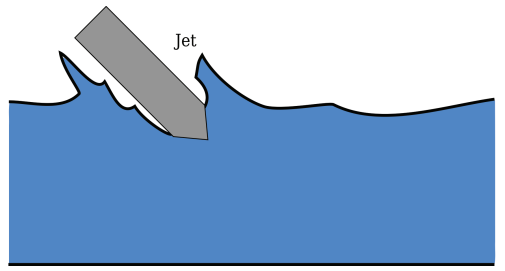

(a)

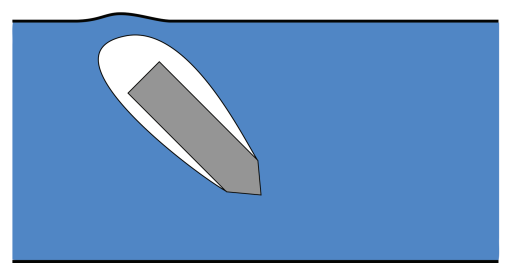

(b)

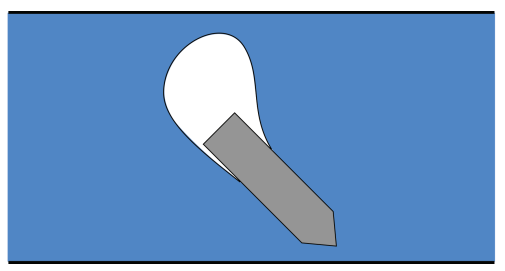

(c)

Figure 3. The several phases of a projectile entering water according to Mackey [Mac79]: (a)

a cavity of air opens; (b) a cavity of air pocket encloses the projectile when it is totally submerged; and (c) the cavity begins to be detached from the projectile, leaving it totally surrounded by water. Some water vapor may exist in the cavity, and cavitation usually

happens. (Adapted from [Abr1 1, p. 060803-2])

mass augmented by the "added mass" of the fluid around the submerged portion of the body. That is,

$$
\text { (1) } \begin{aligned}
\frac{d}{d t}[(M+m(t)) \dot{\zeta}(t)] & =M g-F_{B}-F_{C}-F_{D} \\
& \text { (cf. [Abr11, eq.(2.3)]) }
\end{aligned}
$$

where $M=$ mass of the projectile, $m(t)=$ "added mass," $F_{B}=$ buoyancy force, $F_{C}=$ capillary force, $F_{D}=$ steady-state drag force, and $\zeta(t)=$ depth of penetration into fluid.

We note that the precise value of added mass $m(t)$ is not known. For small time or submerged depth upon entry of the body into the water, von Karman estimated the added mass to be half that of a flat plate with the same area as the instantaneous still water-plane of the body. Wagner [Wag31] further improved von Karman's work by including the effect of the pile up of the water and by associating the added mass with the wetted water-plane. Further work such as [Fab57] took account of the submerged geometry for the estimation of the added mass. The analysis and results from these simple approaches are found to compare favorably with experiments for simple geometries such as a wedge or a cone. They also helped the designs of air-to-subsea anti-submarine missiles, for example.

On the mathematical side, papers studying the water entry problem for a two-dimensional (2D) wedge were written by Shiffman and Spencer [SS51] for a normal incidence problem, and by Garabedian [Gar53] for oblique incidence, for example. These papers treated the case of 2D incompressible, irrotational, inviscid flow by complex variables and potential theory and offered rigorous analysis.

A comprehensive survey of water entry problems (up to the year 2011) can be found in [Abr11], where 476 references are listed, and where a dozen more mathematical (-oriented) papers can also be found.

The splashing and piling up of water waves surrounding the submerged part of the aircraft are close to realism, as the motion of the free (water) surface is modeled and computed by the volume-of-fluid method. We have also used the level-set method and obtained similar graphical results. However, several other physical factors and phenomena have not been taken into account:

(1) The deceleration of the aircraft motion, as its speed is maintained at $70 \mathrm{~m} / \mathrm{sec}$. In addition, in general, the presence of water will cause deflection of the flight path.

(2) At the speed of $70 \mathrm{~m} / \mathrm{sec}$, structural fracture and disintegration of aircraft are likely to occur.

(3) Hydrodynamic force, fluid buoyancy, and drag force have not been incorporated into the model.

Box 1. Commentary on the water-entering motion of aircraft as shown in Figure 1 and its video animation.

The contributions made by von Karman, Wagner, and others were truly remarkable, and they continue to be used today. However, the physics of water entry is far more complex to model than the idea of "added mass" alone. In reality, there are several phases of water entry that have been observed in experiments [Mac79]: (1) cavity-opening and jet splashing; (2) cavity-closing and formation of an air pocket; and (3) cavity-detachment and cavitation; see Figure 3. A good way to capture the rich physics is through state-of-the-art computational fluid dynamics (CFD). The CFD approach will enable us to simulate water entry for complex, general geometries rather than the simplified ones 
such as cones, cylinders, and wedges treated in the early era by encompassing (1) naturally into the two-phase fluid-structure interaction models.

\section{Simulation of the Ditching/Crashing of an Aircraft into Water as a Two-Phase Fluid-Structure Interaction Problem}

Aircraft crashworthiness and human survivability are of utmost concerns in any emergency landing situation. The earth is covered 71 percent by water, and many major airports are situated oceanside. Therefore, the Federal Aviation Administration (FAA) requires all aircraft to be furnished with life vests and the pilots be given water-landing guidlines and manuals.

Assume that an aircraft such as MH370 did not have a midair explosion. Then all available signs indicate that it crashed somewhere in the Indian Ocean. This is an aircraft water-entry problem. Our objective in this section is to conduct numerical simulations for several hypothetical scenarios using CFD.

For a representative Boeing 777 aircraft, we use the values of parameters as given in Table 2 .

The underpinning subject of this study is continuum mechanics, including the water-entry problem first as fluid-structure interaction with a free fluid-gas interface and the subsequent impact and structural failure analysis. Here, water and air are modeled as compressible flows using the NavierStokes equations; cf. Box 2. Our mathematical model is similar to that in Guo et al. [GLQW13].

Table 1. Parameter values for Boeing 777 used in CFD calculations.

\begin{tabular}{|l|r|}
\hline Total weight & $1.8 \times 10^{5} \mathrm{~kg}$ \\
\hline Wing span & $60.9 \mathrm{~m}$ \\
\hline Fuselage cross section & $29.6 \mathrm{~m}^{2}$ \\
\hline Length & $63.7 \mathrm{~m}$ \\
\hline Roll Moment of Inertia & $1.06 \times 10^{7} \mathrm{~kg} \mathrm{~m}^{2}$ \\
\hline Pitch Moment of Inertia & $2.37 \times 10^{7} \mathrm{~kg} \mathrm{~m}^{2}$ \\
\hline Yaw Moment of Inertia & $3.34 \times 10^{7} \mathrm{~kg} \mathrm{~m}^{2}$ \\
\hline
\end{tabular}

We are dealing with two fluids: air and water. Depending on the operating conditions (speed and altitude), we can regard air either as compressible or incompressible. For water, as a liquid, it is generally considered as incompressible. However, if we choose incompressibility as the model for water here, the CFD calculations will have severe difficulty of convergence. A likely cause is that, in water landing situations, local contact interface pressure can get very high, on the order of $10^{6}$ Pascal, causing a compressed state of water. Therefore, we choose compressibility for both air and water as in [GLQW13].

Box 2. Modeling selections: compressible or incompressible?

The CFD software we have adopted here is OpenFOAM, which is open-source and is now widely used by industry and research communities. See an introductory article by several of us in $\left[\mathrm{CXM}^{+} 14\right]$. In particular, we will be using compressibleInterDyMFoam for two-phase flow and RANS $k-\epsilon$ for turbulence modeling. (See some mathematical study on the $k-\epsilon$ turbulence modeling in [RL14, MP93], for example.) Computations were performed on the EOS supercomputer at Texas A\&M University and the RAAD supercomputer at Texas A\&M University at Qatar. For the computational work shown in the examples of this section, each run took one to several days on the campus supercomputers.

We assume that the aircraft is a rigid body. Except for the sample case shown in Figure 1, we did not include the under-wing engines in the Boeing 777 aircraft, with the understanding that the strutmounted engine nacelles would likely be the first things to be torn off in a water-entry situation. (But, computationally, it is straightforward to include the engines in our CFD work as is shown in Figure 1.)

There are two distinct CFD features of this problem:

(a) Because of the relative motion between the aircraft and water, dynamic mesh, or a noninertial frame of reference, must be used. Here we have used a combination of dynamicRefineFvMesh and dynamicMotionSolverFvMesh in OpenFOAM for this purpose.

(b) The free water surface can be treated by using either the volume of fluid method (VOF), [HN81] the level set method [OS88, SSO94], a combination of these two methods [Son03], or the cubic interpolated pseudoparticle method [TNY85]. Because of the availability of the software for VOF in OpenFOAM, VOF is adopted here. 
Table 2. Parameter values for fluid flow used in CFD calculations.

\begin{tabular}{|l|r|}
\hline Atmospheric pressure & $1 \times 10^{5} \mathrm{~Pa}$ \\
\hline Lower bound for pressure & $1 \times 10^{4} \mathrm{~Pa}$ \\
\hline Kinematic viscosity of water & $1 \times 10^{-6} \mathrm{~m}^{2} / \mathrm{sec}$ \\
\hline Kinematic viscosity of air & $1.589 \times 10^{-5} \mathrm{~m}^{2} / \mathrm{sec}$ \\
\hline Water-air surface tension $(\gamma)$ & $0.07 \mathrm{~N} / \mathrm{m}$ \\
\hline Gravitational acceleration $(g)$ & $9.80665 \mathrm{~m} / \mathrm{sec}^{2}$ \\
\hline$\rho_{0}$ in Equation $(6)$ & $1000 \mathrm{~kg} / \mathrm{m}^{3}$ \\
\hline Compressibility of water $\left(\psi_{1}\right.$ in Equation $\left.(6)\right)$ & $1 \times 10^{-5} \mathrm{sec}^{2} / \mathrm{m}^{2}$ \\
\hline Compressibility of air $\left(\psi_{2}\right.$ in Equation $\left.(7)\right)$ & $1 \times 10^{-5} \mathrm{sec}^{2} / \mathrm{m}^{2}$ \\
\hline Constants in $k-\epsilon$ turbulence model & $C_{\mu}=0.09, C_{1}=1.44, C_{2}=1.92, \sigma_{\epsilon}=1.3$ \\
\hline Initial values for $k-\epsilon$ turbulence model & $k=0.1 \mathrm{~m}^{2} / \mathrm{sec}^{2}, \epsilon=0.1 \mathrm{~m}^{2} / \mathrm{sec}^{3}$ \\
\hline Initial aircraft speed relative to stationary water $\left(V_{0}\right)$ & $\left.58 \mathrm{~m} / \mathrm{sec}^{2} \approx 130 \mathrm{mph}\right)$ \\
\hline
\end{tabular}

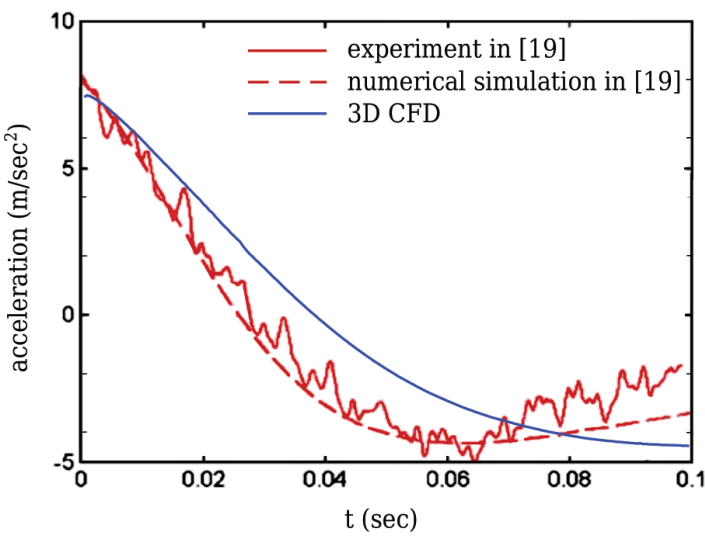

(a) deadrise angle is $\pi / 4$, effective gravity is $8.0062 \mathrm{~m} / \mathrm{sec}^{2}$, mass of wedge is $13.522 \mathrm{~kg}$, speed at water entry is $0.95623 \mathrm{~m} / \mathrm{sec}$.

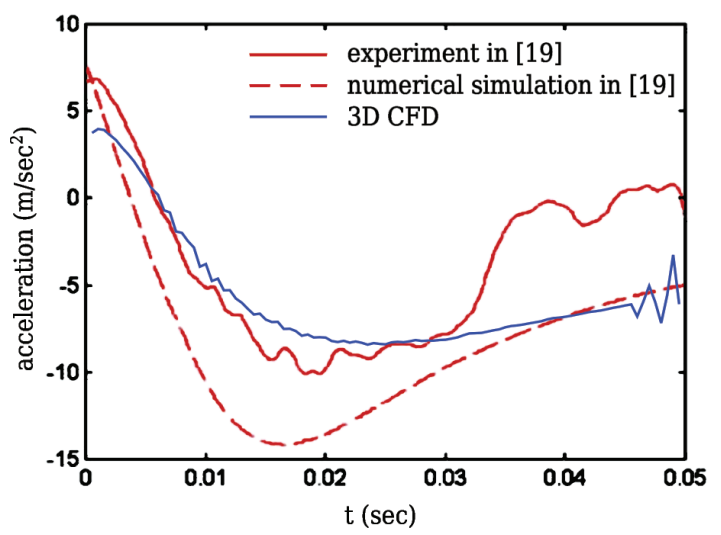

(c) deadrise angle is $\pi / 9$, effective gravity is $7.8144 \mathrm{~m} / \mathrm{sec}^{2}$, mass of wedge is $12.952 \mathrm{~kg}$, speed at water entry is $0.86165 \mathrm{~m} / \mathrm{sec}$.

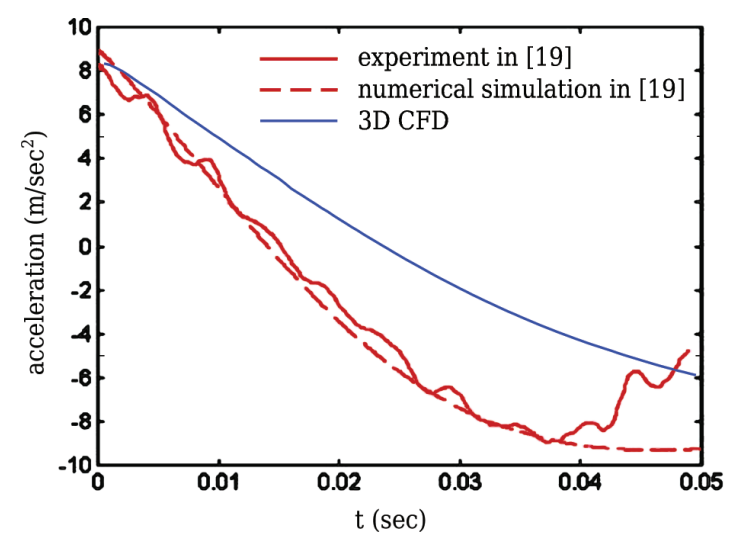

(b) deadrise angle is $\pi / 4$, effective gravity is $8.9716 \mathrm{~m} / \mathrm{sec}^{2}$, mass of wedge is $30.188 \mathrm{~kg}$, speed at water entry is $1.69673 \mathrm{~m} / \mathrm{sec}$.

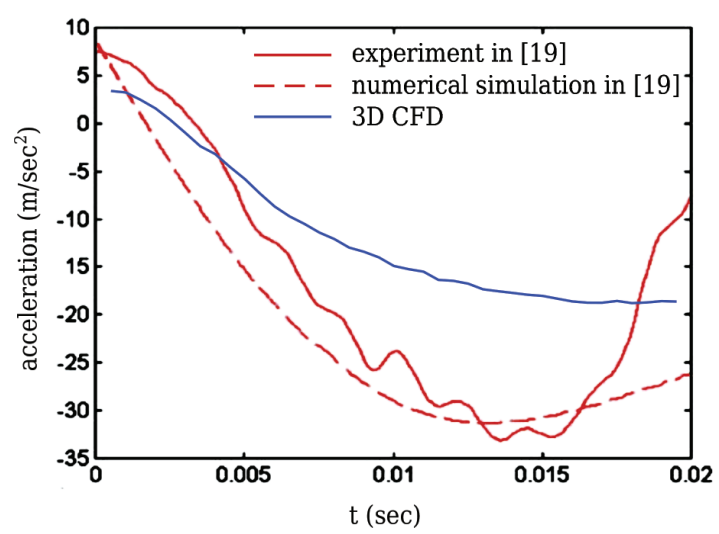

(d) deadrise angle is $\pi / 9$, effective gravity is $8.6103 \mathrm{~m} / \mathrm{sec}^{2}$, mass of wedge is $29.618 \mathrm{~kg}$, speed at water entry is $1.54405 \mathrm{~m} / \mathrm{sec}$.

Figure 4. Curves of acceleration versus time as benchmarks in comparisons with Wu et al. Graphs reprinted from [WSH04, p. 28], with permission from Elsevier. The curves obtained from experiment and numerical simulations are compared under different settings. The blue curves represent the data obtained by our computational methods in this paper. 


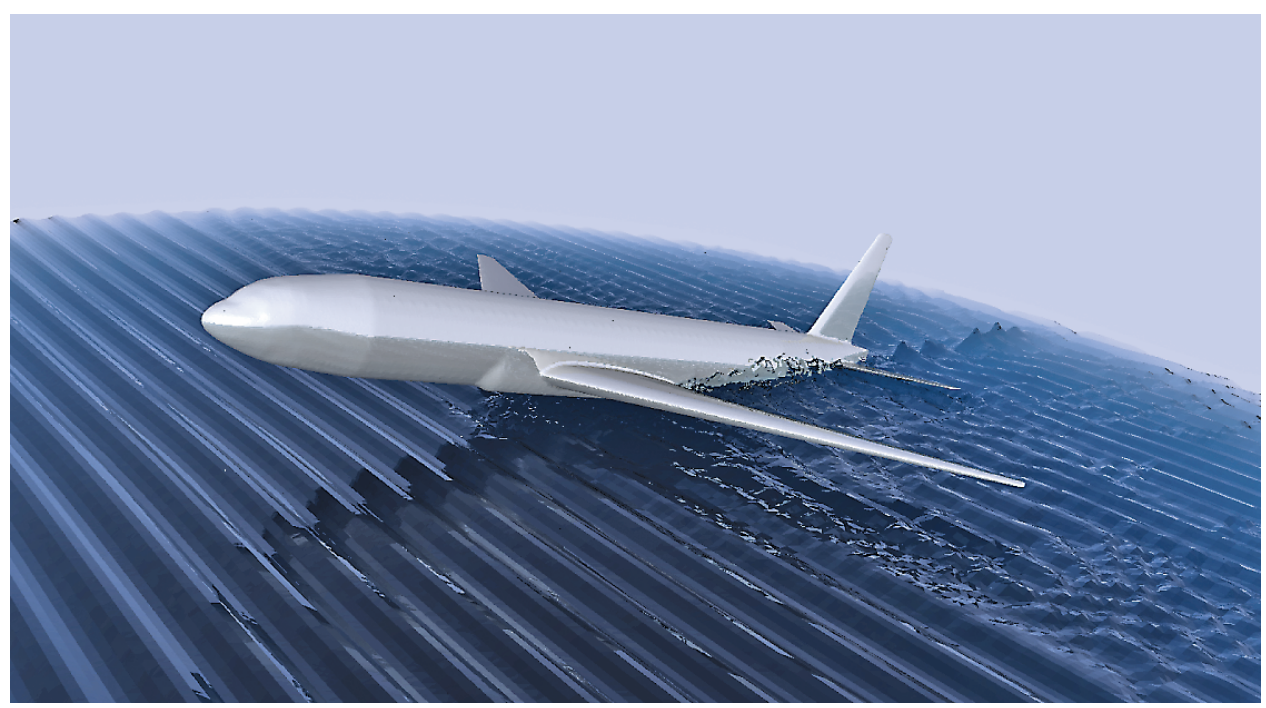

(a) gliding water entry

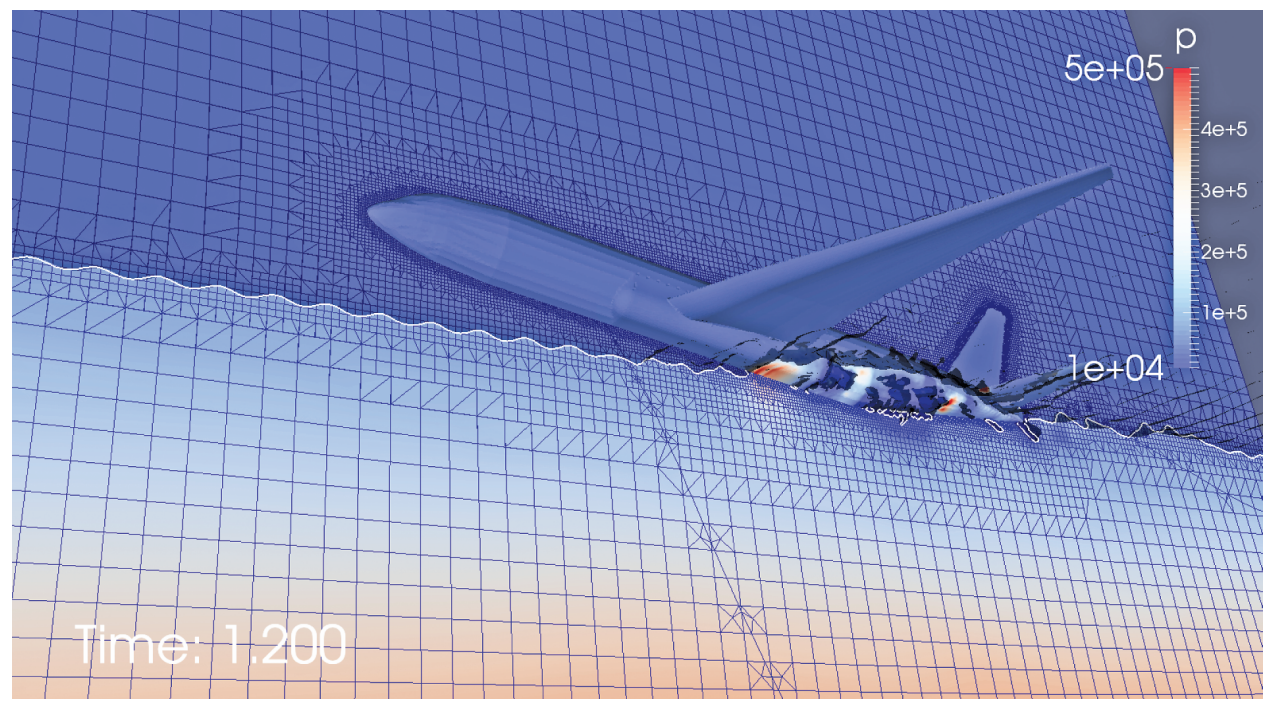

(b) pressure distribution and mesh

Figure 6. Pitch angle $=8^{\circ}$, angle of approach $=1^{\circ}$. This corresponds to Case 1 ; a video animation can be viewed at https://www. dropbox. com/s/zpme04bmakien2h/comb8. mp4. The animation has two parts: the first part shows the water flow pattern, while the second is intended to show the pressure distribution. (This is the same for all video animations corresponding to the remaining figures in this section.)

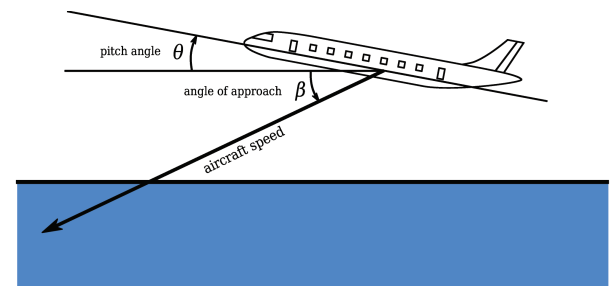

Figure 5. Angle $\theta$ here is the pitch angle signified in the computations of cases 1-5 and $\beta$ is the angle of approach. The speed of the aircraft denotes the speed of its center of mass.
Equations for the volume of fluid two-phase problem are the following:

- Conservation of mass for each phase

$$
\frac{\partial\left(\rho_{i} \alpha_{i}\right)}{\partial t}+\nabla \cdot\left(\rho_{i} \alpha_{i} \mathbf{u}\right)=0
$$

where $\alpha_{i}, i=1,2$, are volume fractions of each phase satisfying $\alpha_{1}+\alpha_{2}=1$.

(3)

- Conservation of momentum

$\frac{\partial(\rho \mathbf{u})}{\partial t}+\nabla \cdot(\rho \mathbf{u u})=-\nabla p+\nabla \cdot \mathcal{T}+\rho \mathbf{g}+\gamma \kappa \nabla \alpha_{1}$, 
where $\mathcal{T}$ is the deviatoric portion of the total stress tensor

$$
\mathcal{T}=\mu\left(\nabla \mathbf{u}+\nabla \mathbf{u}^{\top}\right)-\frac{2}{3} \mu \mathcal{I} \nabla \cdot \mathbf{u}
$$

with $\mathcal{I}$ being the identity tensor. $\rho$ and $\mu$ being effective density and viscosity fields for the mixture, respectively, $\gamma$ being the surface tension, and $\kappa$ being phase interface curvature

$$
\kappa=-\nabla \cdot\left(\frac{\nabla \alpha_{1}}{\left|\nabla \alpha_{1}\right|}\right) .
$$

Note that the air-water interface condition is embedded in the $\nabla \alpha$ term in (3).

- Equation of State

(6)

(7)

$$
\begin{gathered}
\rho_{1}=\rho_{0}+\psi_{1} p \quad \text { (for water), } \\
\rho_{2}=\psi_{2} p \quad \text { (for air). }
\end{gathered}
$$

These equations model isothermal processes in air and water. The physical meaning of $\psi_{j}(j=1,2)$ here is $1 / c_{j}^{2}$ where $c_{j}$ is sound speed in the medium.

- Six degrees of freedom of motion

$$
\begin{gathered}
\boldsymbol{\sigma}=-p \boldsymbol{I}+\boldsymbol{T}, \\
\mathbf{F}(t)=\text { force }=\int_{\partial \Omega(t)} \boldsymbol{\sigma} \hat{\mathbf{n}} d S, \\
\boldsymbol{\tau}(t)=\text { torque }=\int_{\partial \Omega(t)} \mathbf{r} \times \boldsymbol{\sigma} \hat{\mathbf{n}} d S .
\end{gathered}
$$

The exterior of the domain occupied by the aircraft is denoted as $\Omega(t)$ (depending on $t$ due to aircraft motion), and $\partial \Omega(t)$ is its boundary. The boundary velocity $\mathbf{V}(\mathbf{x}, t)$ for $\mathbf{x} \in \partial \Omega(t)$ can be subsequently computed from (9) in rigid body dynamics.

- Moving boundary condition on aircraft skin

$$
\left.\mathbf{u}\right|_{\partial \Omega(t)}=\mathbf{V}(\mathbf{x}, t) \text {. }
$$

Note that at time $t=0$, the velocity of the aircraft's center of mass is $V_{0}$ along various angles of approach; cf. Table 1. This, together with equations (2)-(9), constitute the complete initial-boundary value problem for the numerical computation. Various physical and computational parameter values are listed in Table 1.

Remark 1. Every CFD treatment needs to be validated. Why? CFD approaches have their roots in theory, experiments, and computation. Validation determines whether the computational results agree with physical reality - the experimental data. CFD codes must produce numerical results of desired accuracy so that they can be used with confidence. Here we use the experimental data available in [WSH04] for a simplified scenario, that is, a constrained free-falling "wedge" entering water. The wedge has only the vertical translational degree of freedom. The acceleration(/deceleration) of the wedge is measured throughout its impact with the water. The study in [WSH04] also employed a 2D potential flow model to study the problem numerically. In order to validate our CFD method, the setup for the experiment is replicated as a 3D mesh. Figure 4 shows the comparison of the acceleration time curves with a variety of parameters. (One of the varying parameters, the "deadrise angle", is defined as the angle formed between the angled side of the wedge with the horizon.) Although some differences of values are observed, our CFD simulation shows a strong qualitative match of the acceleration/deceleration curves. We also note that the numerical model in [WSH04] is a very simplified one, without the incorporation of several aero-hydrodynamic effects.

Aviation experts generally agree that how the airliner enters the water determines its breakup, which then yields major clues and directions of the search operations [syr]. Therefore, in the following, we provide five scenarios of water entry. In each case, we provide comments, schematics, snapshots, and a CFD animation. Each animation consists of two parts, with the first part showing visual effects and the second part showing pressure loading.
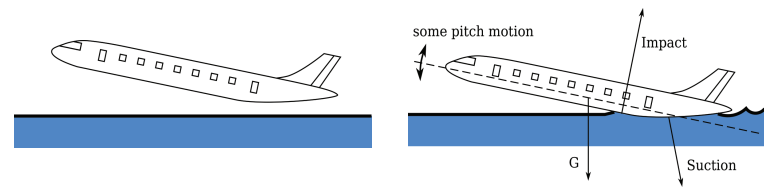

Figure 7. Schematics for the process of glided ditching. Major forces are illustrated. This corresponds to Case 1.

Case 1: pitch angle $=8^{\circ}$, angle of approach $=1^{\circ}$ This is what one might call glided ditching, similar to the US Airways Flight 1549 mentioned in the first section; see Figure 6 and the accompanying animation. The vertical component of the airline's velocity is found from (13) in the next section to be $1-2 \mathrm{~m} / \mathrm{sec}$. This is much smaller than the critical speed $V_{c r}=15-20 \mathrm{~m} / \mathrm{sec}$ for structural failure in the next section and, thus, is good. See also Figure 7 for the interpretations of motion.

Case 2: pitch angle $=-3^{\circ}$, angle of approach $=3^{\circ}$

See Figure 8 and its animation. Here we see an interesting phenomenon; namely, even though the original pitch angle is negative, the aircraft will "bounce" on the water and make the pitch angle positive. See Figure 9. At the moment this happens, the bottom of the midsection (fuselage-water contact surface) of the aircraft undergoes high bending moment and surface pressure. This may cause the aircraft to break up in 


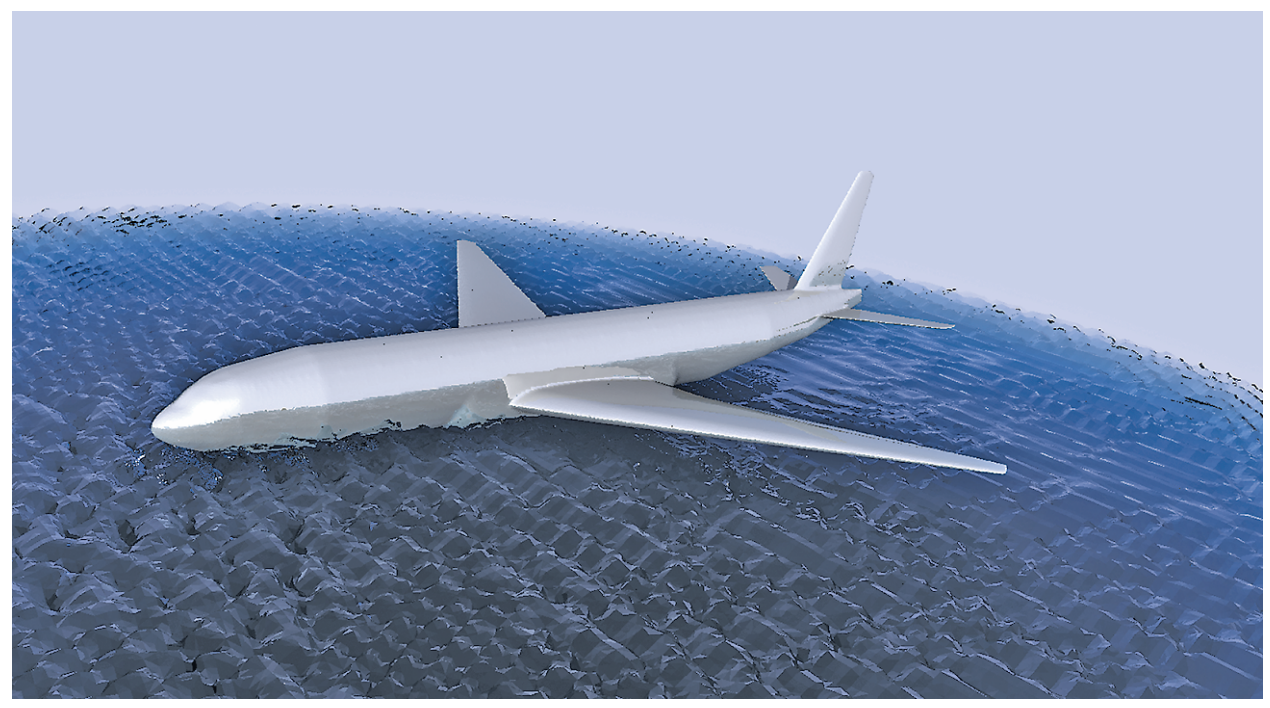

(a) gliding water entry (with a negative initial pitch)

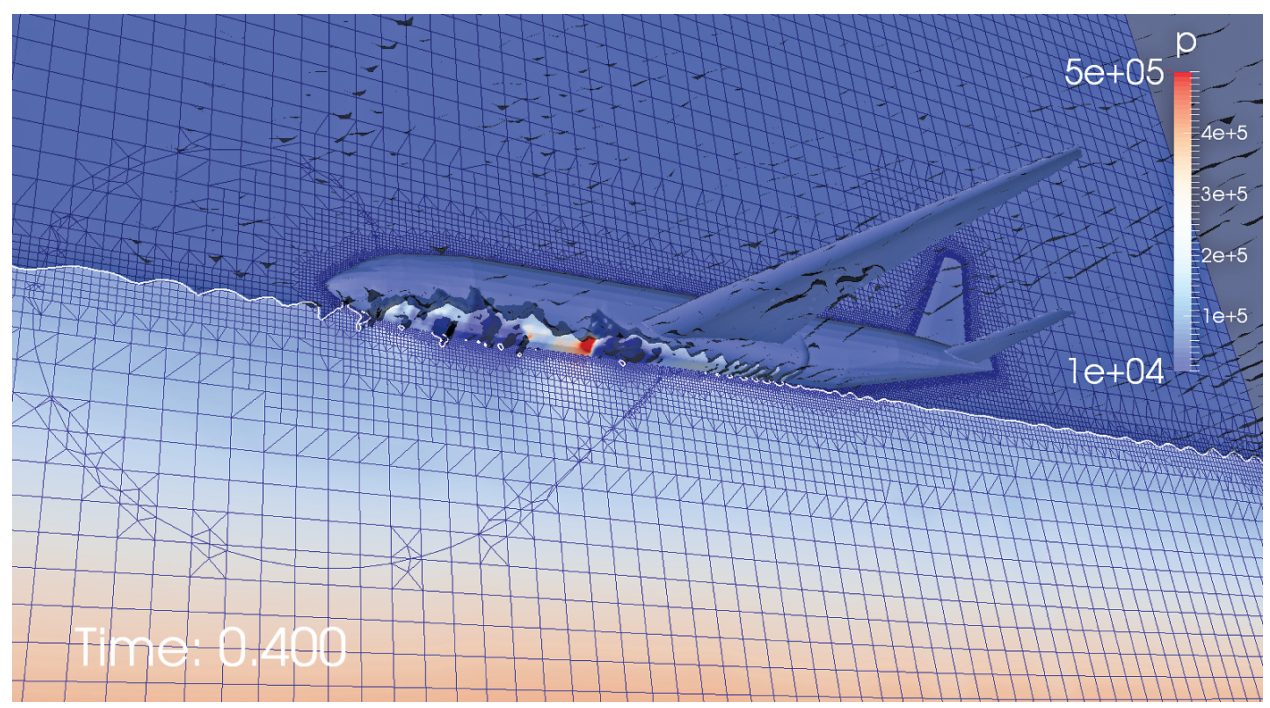

(b) pressure distribution and mesh

Figure 8. Pitch angle $=-3^{\circ}$, angle of approach $=3^{\circ}$. This corresponds to Case 2. A video animation can be viewed at https://www. dropbox. com/s/6zakw7js7kbcwed/comb-3 . mp4.

the middle section, a global failure to be described in the following section.

Case 3: pitch angle $=-30^{\circ}$, angle of approach $=30^{\circ}$ See Figure 10 and its animation. Here we see that the aircraft nose is subject to high pressure throughout the time sequence. See also the schematics in Figure 11 in contrast to Figure 9. Once the wings enter the water, the leading edge of the wing is subject to high pressure loading up to $10^{6}$ Pa.

Case 4: pitch angle $=-90^{\circ}$, angle of approach $=$ $93^{\circ}$

See Figure 12 and its animation. This is a nose-dive situation. Here we further assume that the ocean current flows from left to right at a velocity of $3 \mathrm{~m} / \mathrm{sec}$. Then, once the aircraft enters the water, the current gradually drives the aircraft toward the 5 o'clock direction. Eventually this could cause it to fall on the ocean floor belly-up. See Figure 13. Cf. more discussions in Box 3.

Case 5: pitch angle $=-3^{\circ}$ with roll angle $=20^{\circ}$, angle of approach $=3^{\circ}$

See Figure 14 and its animation. Here, with a 20-degree roll, the left wing of the plane enters the water first. Almost inevitably, this would cause structural failure of the left wing. Read more in Box 4 about an air 


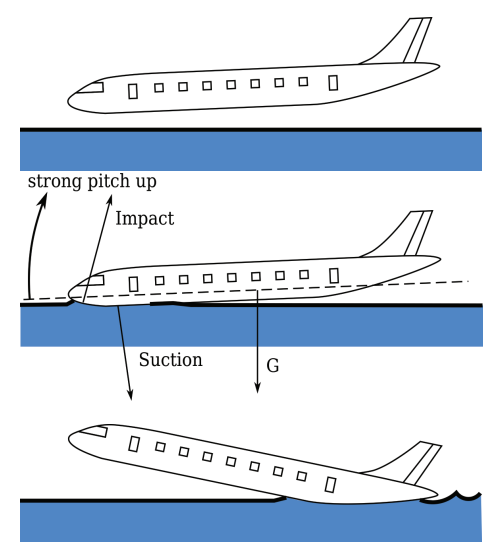

Figure 9. Schematics for the process of ditching with negative initial pitch. The plane is able to recover to the glided ditching attitude ${ }^{1}$ similar to Figure 7. This corresponds to Case 2. disaster on the seaside of Comoros Island, Africa.

\section{Damage and Breakup}

As described in the Introduction, not all emergency water landings end in disaster. The dramatic successful landing in the "Miracle on the Hudson" is such a case. The fact that no lives were lost is a testament to the experience and fast thinking under pressure of the captain and crew. The aircraft had a hole ripped open but was otherwise structurally virtually intact. The speed of the aircraft at ditching was estimated to be $150 \mathrm{mph}(240 \mathrm{~km} / \mathrm{hr}$ or 67 $\mathrm{m} / \mathrm{sec}$ ). It was deemed by NTSB as "the most successful ditching in aviation history." [23]

In addition to the Comoros Island air disaster in Box 4, we mention another ditching effort whose outcome was not as fortunate as the US Airways flight 1549. On August 6, 2005, a Tuninter Airlines Flight 1153 ATR-72 aircraft, flying from Bari International Airport, Bari, Italy, to Djerba-Zarzis Airport, in Djerba, Tunisia, ran out of fuel and ditched into the Mediterranean $43 \mathrm{~km}$ northeast of Palermo, Italy. Upon impact, the aircraft broke up into three pieces. Sixteen persons out of the thirty nine passengers and crew died. Eight of the deaths were actually attributed to drowning after the bodily injuries from impact.

In the numerical simulations provided in the preceding section, we have not included the effects of rupture and structural disintegration. But they are almost certain to happen upon the entry of the aircraft into water when the speed is sufficiently high. This happened even in the "Miracle on the Hudson" case with smooth gliding. The study of impact damage and breakup belongs to a field called impact engineering, which is based on the plasticity and fracture properties of solids that are

\footnotetext{
${ }^{1}$ Note: "ditching attitude" is an academic term.
}

totally different from the fluid dynamics issues we have been discussing up to this point.

Due to the limited scope of this article, we can't delve too much into the study of impact effects. Nevertheless, we can use another famous example, the disaster of the Space Shuttle Challenger, to understand what may happen, based on the analysis of one of the coauthors (Wierzbicki) in [WY86b, WY86a].

If an aircraft stalls in a climb, or if any control surfaces-ailerons, rudder, or stabilizersmalfunction, or if it runs out of fuel and the autopilot stops working (while the pilots are incapacitated or if the action is deliberate), it can fall into a steep nose-dive or even vertical drop (our Case 4 here).

What happens upon water-entry? Here, we directly quote [syr]:

"...The wings and tail would be torn away and the fuselage could reach a depth of 30 meters or 40 meters within seconds, then sink without resurfacing. Wing pieces and other heavy debris would descend soon afterward.

Whether buoyant debris from the passenger cabin-things like foam seat cushions, seatback tables and plastic drinking water bottles-would bob up to the surface would depend on whether the fuselage ruptured on impact, and how bad the damage was.

"It may have gone in almost complete somehow, and not left much on the surface," said Jason Middleton, an aviation professor at Australia's University of New South Wales..."

This may well offer a powerful clue as to why, so frustratingly, none of the debris of MH370 has been found so far.

\section{Box 3. Does nose-dive have anything to do} with the lack of debris?

The airframe of the Space Shuttle Challenger, an assemblage of ring and stringer-stiffened panels, was constructed essentially like a wide-body Boeing 747 airliner. This in turn is similar to a wide-body aircraft such as the example Boeing 777 under discussion here. Thus, we expect that much of the material and structural failure analysis performed in [WY86b, WY86a] for Challenger continues to hold.

There is a distinction between the following:

(i) global failure mode of fuselage, caused by large contact forces between water and structure;

(ii) local failure mode due to excessive pressure.

Both such contact forces and pressure vary spatially and temporally. They are obtained from the CFD part of the solution in the preceding section and used to assess the damage. In the 


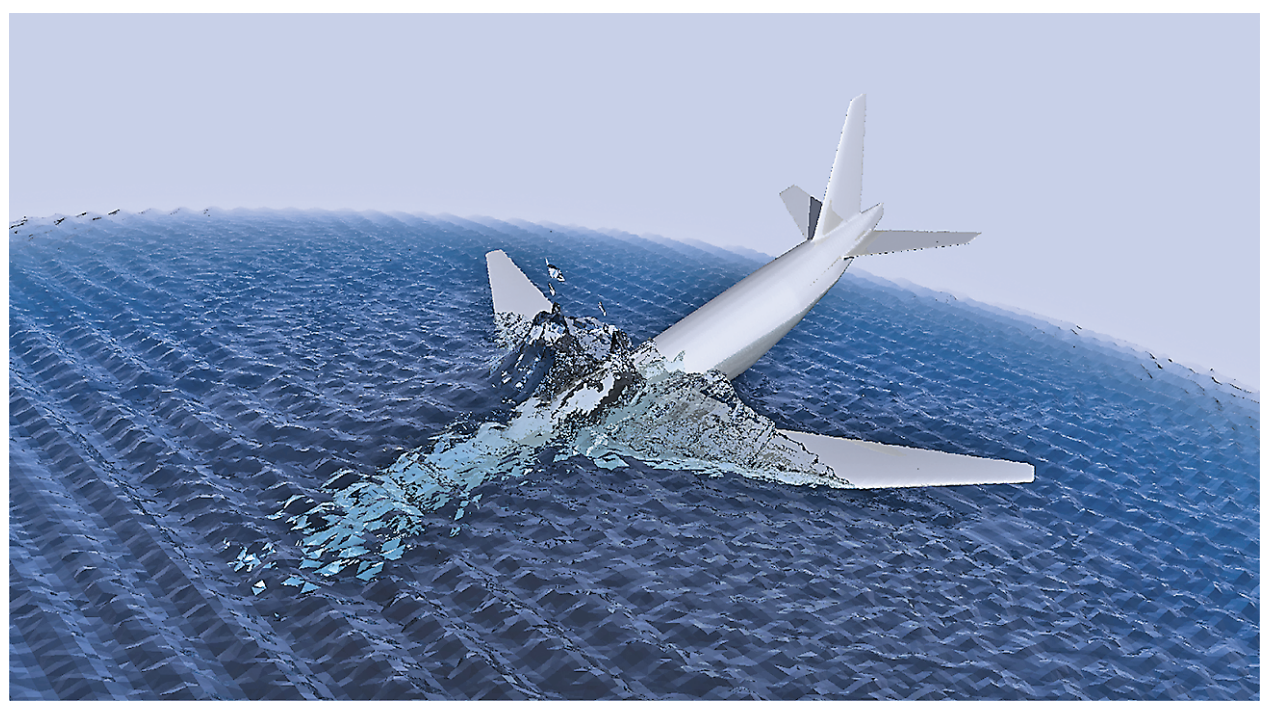

(a) diving water entry

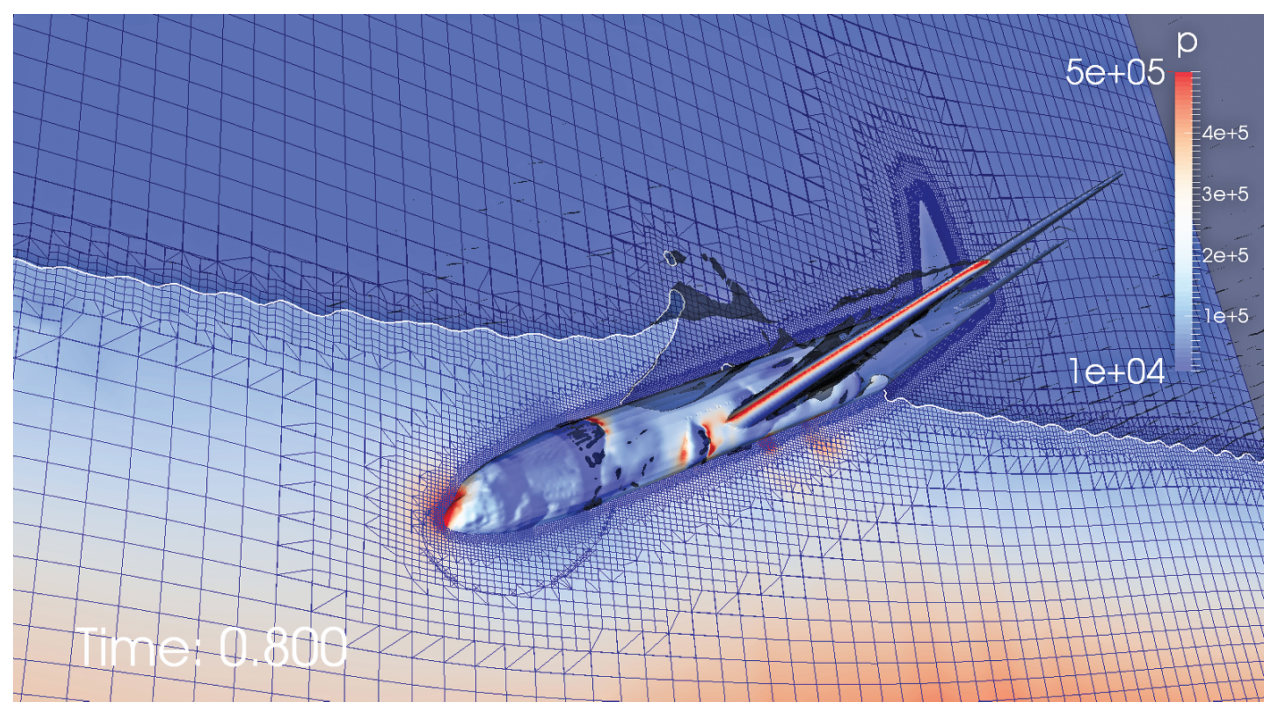

(b) pressure distribution and mesh

Figure 10. Pitch angle $=-30^{\circ}$, angle of approach $=30^{\circ}$. This corresponds to Case 3 . A video animation can be viewed at https://www. dropbox. com/s/8iyj9xws4d90avk/comb-30. mp4

analysis of global failure, simple structural models of beams and rods are used for the fuselage. In what follows, we give a quick review of how to study structural breakup upon impact, but defer the more technical study to a sequel.
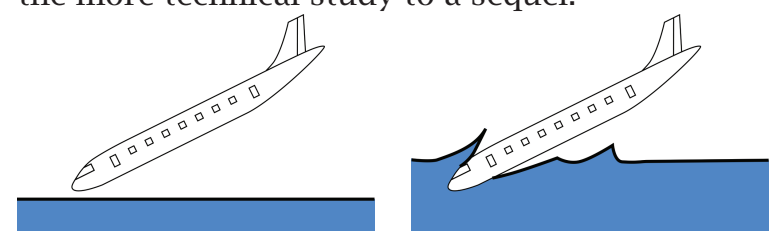

Figure 11 . The pitch angle is too negative to recover to the glided ditching attitude. The plane's nose dives into the water with little bouncing motion. This corresponds to Case 3 .
A flying aircraft was modeled in [WY86b] as a free-free beam with known spatial and temporal variation of external loading, where the distribution of bending moments can be uniquely found from the equations of dynamic equilibrium. Thence, the maximum cross-sectional bending moment can be compared with the fully plastic bending capacity of the fuselage. This will indicate the onset of structural collapse and break up.

The local failure mode is composed of tearing of fuselage skin as well as tensile and shear rupture of the system of stringers and ring frames; cf. Figure 15. Depending on the impact velocity, the local failure can involve progressive buckling and folding of the fuselage or fragmentation. Such 


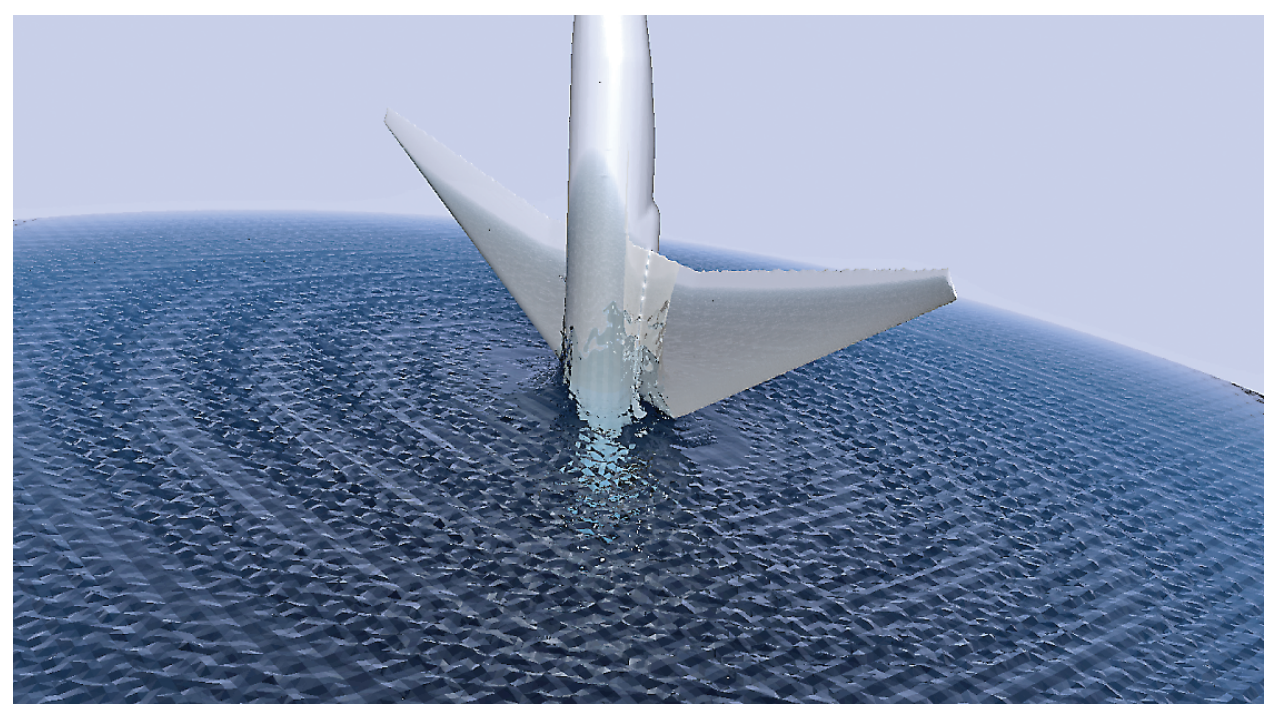

(a) nose-dive water entry

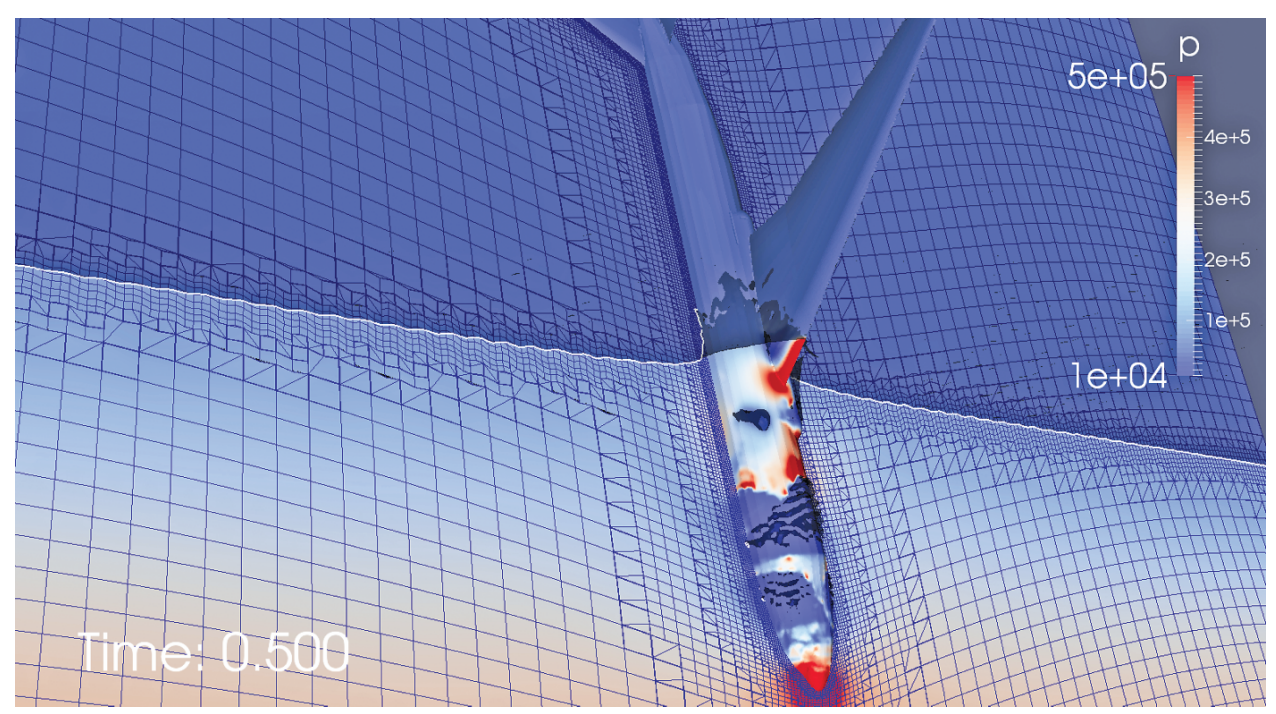

(b) pressure distribution and mesh

Figure 12. Pitch angle $=-90^{\circ}$, angle of approach $=93^{\circ}$. This corresponds to Case 4 . A video animation can be viewed at https://www. dropbox.com/s/vaf0qenjw01k5yz/comb-90. mp4.

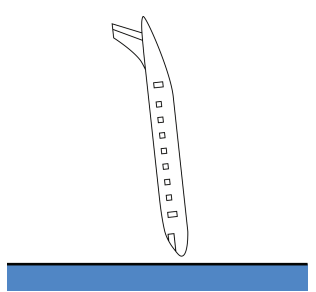

(a)

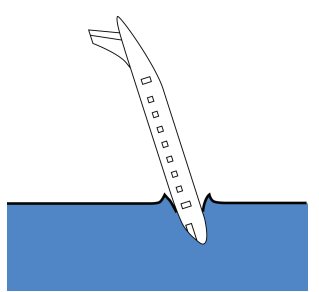

(b)

Figure 13. Schematics for nose-diving. The ocean current pushes the aircraft to the right, causing it possibly to finish belly-up on the ocean floor. This corresponds to Case 4. 


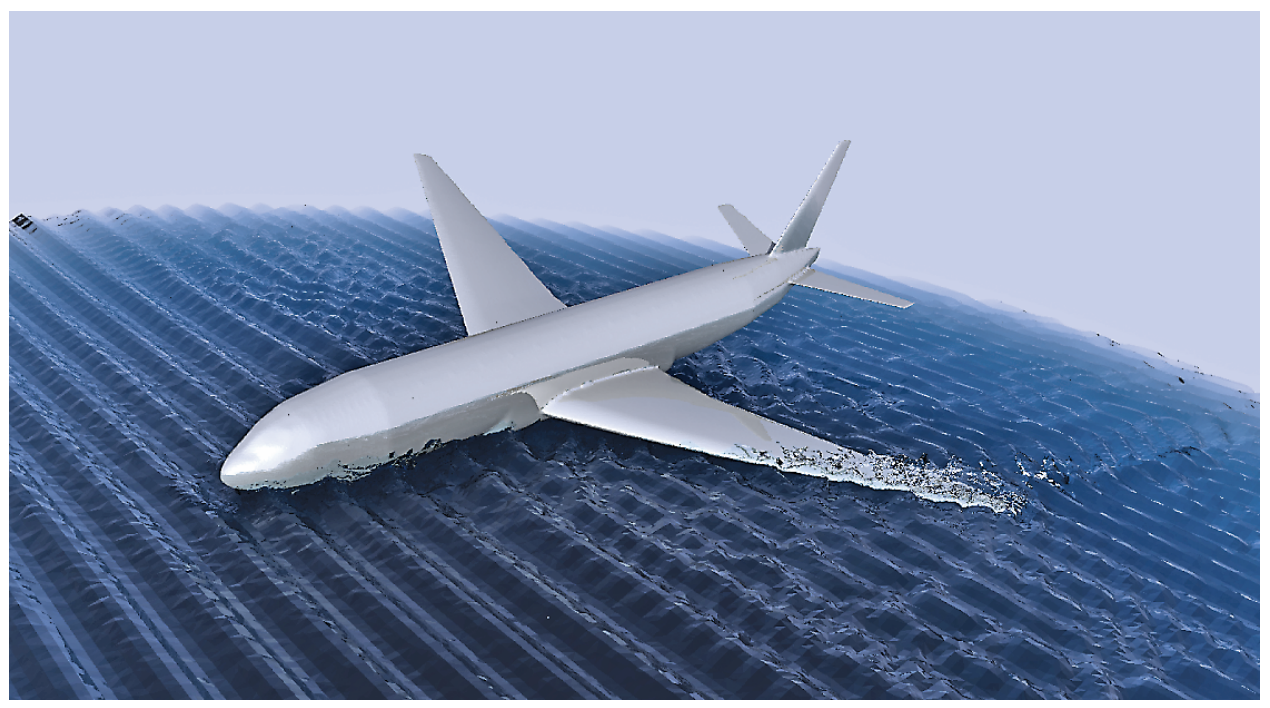

(a) rolling water entry

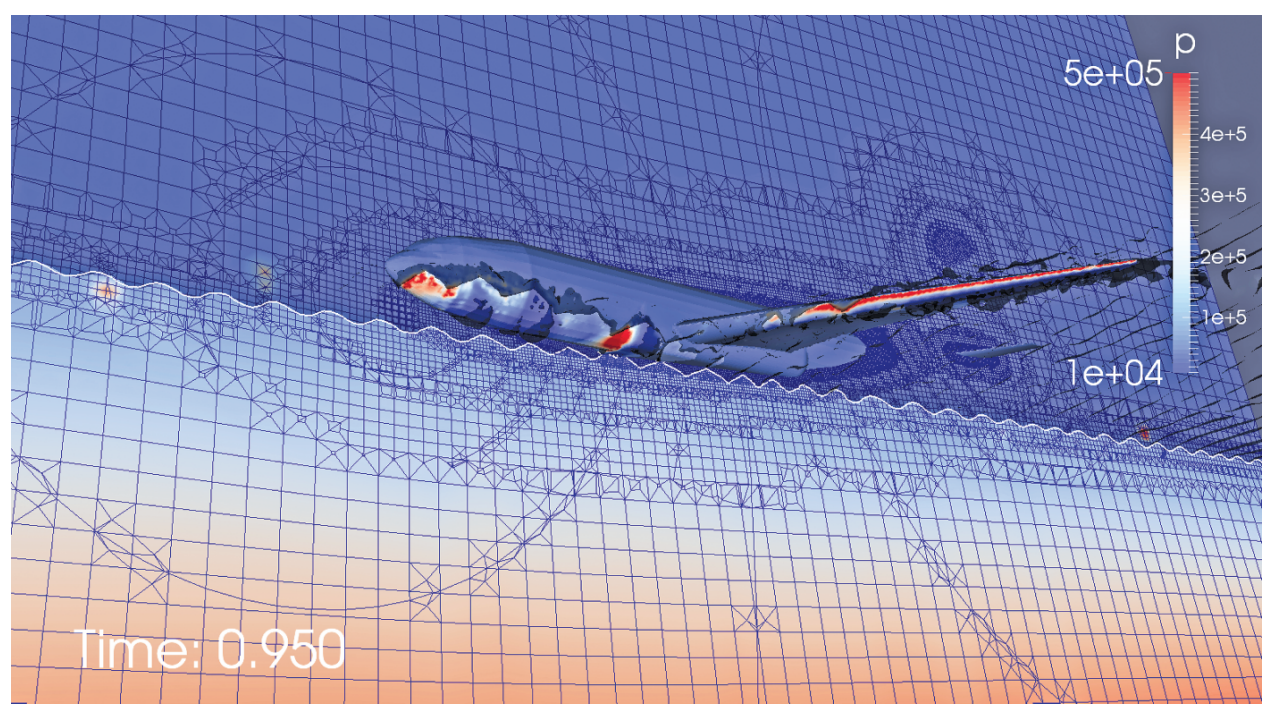

(b) pressure distribution and mesh

Figure 14. Pitch angle $=-3^{\circ}$, angle of approach $=3^{\circ}$, but with a left-roll angle of $20^{\circ}$. This corresponds to Case 5. A video animation can be viewed at https://www. dropbox. com/s/cgvn99okc4ao0i4/combSide. mp4.

There is an incredible complete video recording of this air disaster, available for viewing at www. youtube. com/watch? $\mathrm{v}=\mathrm{sKC}$ COCHCNH8.

The hijacked wide-body Boeing 767-260ER jetliner flew and rolled into the ocean with the left wing clipping water and getting torn off first. Immediately afterward, the same happened to the right wing. The fuselage went into cartwheeling and broke up. Only fifty of the 175 crew and passengers survived.

Debris spread over a wide area, and the light pieces could have floated for a long time.

Box 4. A rolling water-entry case: hijacked Ethiopian Airlines Flight 961 ditching by Comoros Island, Africa in 1996.
Fracture failure mode is estimated to happen when the vertical component of velocity exceeds certain critical value $V_{c r}$. Rupture of fuselage and wings as shear and tensile cracks will be initiated and then propagate through the stiffened shell, leading to global structural failure. This is a dynamic process whose analysis is very challenging. Nevertheless, a simple estimate on the onset of local failure can be given using the condition of dynamic continuity in uniaxial wave propagation along a rod based on the equation

$$
[\sigma]=\rho c[u]
$$




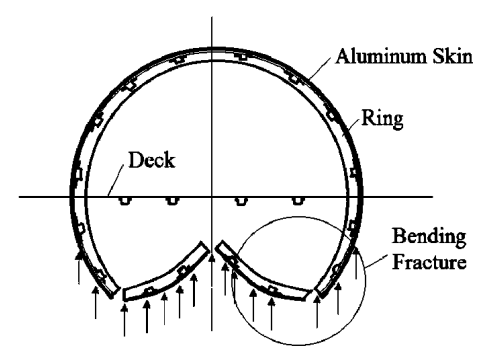

(a)

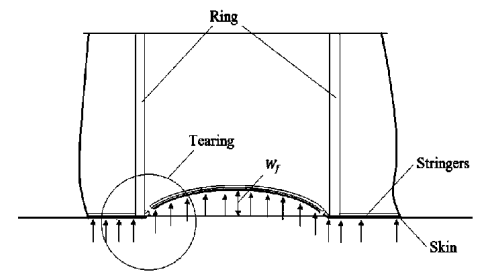

(b)

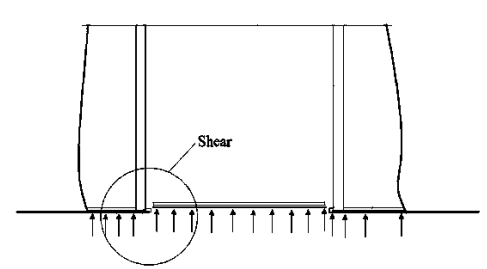

(c)

Figure 15. Three modes of structural failure for a wide-body airliner: (a) flexural failure of rings; (b) tearing fracture; and (c) shear of the longitudinally stiffened shell. (Adapted from [WY86b, p. 651])

where $[\sigma]$ and $[u]$ denote jump discontinuities across the water-structure interface, $\rho=2.8 \mathrm{~g} / \mathrm{cm}^{3}$ is the mass density of the aluminum fuselage, and $c=\sqrt{E / \rho}$ is the speed of the uniaxial wave propagation in an elastic rod with elastic modulus $E=85$ GPa (i.e., $10^{9}$ Pascal). The critical impact velocity $V_{c r}$ (vertical component only) is reached when the stress equals the yield stress of the material $\sigma_{y}$. Thus, from (11) one gets the following estimate on $V_{c r}$ :

$$
V_{c r}=\frac{\sigma_{y}}{E} c .
$$

Depending on the material, the critical descending speed of aircraft is normally in the range of $V_{c r}=15-20 \mathrm{~m} / \mathrm{sec}$. A common fuselage material is 2024 T351 aluminum alloy with the yield stress of $\sigma_{y}=324 \mathrm{MPa}\left(10^{6}\right.$ Pascal). The critical impact velocity is thus $V_{c r}=22 \mathrm{~m} / \mathrm{sec}$, which is close to the value $18.8 \mathrm{~m} / \mathrm{sec}$ predicted for the water ditching of the Space Shuttle Challenger, but using a different approach in [WY86b]. The vertical component $V_{c r}$ of $V_{0}$, the aircraft speed at ditching, is related through the angle of approach $\beta$ by

$$
\sin \beta=\frac{V_{c r}}{V_{0}} .
$$

Therefore, it is essential to keep the angle of approach small, especially when ditching with a high speed.

In addition to structural rupture and disintegration, the acceleration due to free fall and the deceleration due to the impact of the structure are important for human survival in a crash. In [WY86b], it was analyzed that if the vertical component of the terminal impact velocity lies in the range of $62.5 \mathrm{~m} / \mathrm{sec}$ and $80.5 \mathrm{~m} / \mathrm{sec}$, maximum decelerations could reach in the order of $100 \mathrm{~g}$ to $150 \mathrm{~g}$ ( $\mathrm{g}$ is the gravitational acceleration constant) over a short period of time, within a regime labeled "severe injuries" [WY86b, MHV59] by NASA.

Remark 2. According to the numerical simulation results in the preceding section, the airliner's skin will be subject to surface pressure in the order of $6 \mathrm{MPa}$, which is considerably smaller than the yield stress $324 \mathrm{MPa}$ of the $2024 \mathrm{~T} 351$ aluminum alloy's. Thus, at the given (very low!) speed of ditching, $58 \mathrm{~m} / \mathrm{sec}$, there appears to be no local fracture due to yield stress. Any of the structural failures must happen at weak joints, strut-mounts, and stringer-stiffeners where the engine nascelles, wings, and fuselage are connected. These belong to the category of global failures.

The decelerations from computation indicate a maximum deceleration for all five cases to be about $6 \mathrm{~g}$, which is far smaller than the dangerous decelerations of $100 \mathrm{~g}$ to $150 \mathrm{~g}$ at the end of Remark 1. But the magnitude of decelerations could be far greater if the speed at ditching is large.

As a consequence of this, it now becomes clear that the vertical component of the terminal water-entry velocity should be reduced as much as possible, such as the glided water-landing approach taken by Captain Sullenberger for US Airways Flight 1549 on the Hudson River. That is, some "pitching attitudes" of the aircraft will yield a much higher probability of survival by averting structural damage and decelerations of the occupants [WY86a, 
p. 34]. Indeed, according to Guo, et al. [GLQW13], it is recommended that, for a transport aircraft with a low horizontal tail, the pitch angle be chosen between $10^{\circ}$ and $12^{\circ}$ (with an angle of approach of $1^{\circ}$ ) for safer ditching, which is consistent with the prediction of (13). Such knowledge enhances air travel safety and, as shown here, can be obtained by CFD simulations.

\section{Concluding Remarks}

After viewing the five cases of simulation for an airliner's water entry and with some rudimentary knowledge about resulting damages in the preceding two sections, one naturally raises the question:

Which case is the most likely scenario for the final moments of Flight MH370?

Our assessment is Case 4; namely, the nosedive water-entry or a water-entry with a steep pitch angle, is the most likely scenario. This particular assertion is speculative but forensic, based mainly on the observations of the computed data in the prior section, combined with the understanding of aviation precedents, atmospheric and ocean surface conditions, due to the following:

(a) So far, there is a total lack of floating debris. Similarly, oil spills have not been observed, hinting that the aircraft ran (almost) out of fuel before crashing.

(b) A smooth gliding water-entry as in Case $\mathbf{1}$ (similar to US Airways Flight 1549) may result in only small rupture. But ditching a large airplane on the open Indian Ocean generally would involve waves of height several meters or more, easily causing breakup and the leak of debris.

(c) As already noted, Case 2 suffers large bending moment, and buckling and breakup can ensue.

(d) For Case 3, rough waves may also cause breakup and the leak of debris.

(e) For Case 5, as we have seen from the video recording in Box 4, there is a high likelihood of breakup in some middle section of aircraft.

This leaves Case 4 as the main possibility why no floating debris has been spotted. Again, this assessment is of a speculative character as our computer simulations have not included all aircraft speeds and ocean surface conditions, and the effects of bending moments. The mystery of the final moments of MH370 is likely to remain until someday when its black box is found and decoded.

The crash of an airliner into ocean is a profoundly tragic event. But on the mathematical and engineering side, there should be significant interest in its modeling and computation so that one can understand the physical mechanisms better in the hope of improving aircraft crashworthiness and survivability. The CFD approach is advantageous in saving long and expensive processes of laboratory setup and measurements. Now, with the availability of increased free and open-source computational tools and user-friendly software, it has become much easier for mathematicians to conduct interdisciplinary collaboration with engineers and physicists for the modeling and computation of complex, "real world" problems, just as this article has hoped to demonstrate. Many challenges remain. Regarding CFD for the study of aircraft ditching in water, see an excellent review and outlook paper in Liu et al. [LQG ${ }^{+} 14$ ]. For an analysis-minded mathematician, it would be nice to formulate a list of problems dealing with the rigor of generality of approach, robustness, and stability issues, which are being considered.

A body of literature already exists for the computer simulation of rupture and disintegration of a crashing aircraft (on land or into buildings). The software by Abaqus [Aba], LS-DYNA [lsd] and others is known to be able to simulate the impact and breakup of solids in collisions. But this component of the problem is too technical and must be deferred to a sequel.

On any given day, there are hundreds of thousands of people traveling by air worldwide. Air travel has never been safer and continues to become even safer. According to Barnett [Bar10], in the 2000-2007 time period, the death risk per flight on a first-world airliner was 1 in every 2 million: and 2 million days is nearly 5,500 years! There are always bound to be unfortunate and tragic incidents. However, it is to be expected that data generated by numerical simulations will further improve passenger survival in emergency water landings.

\section{Acknowledgment}

We are indebted to Prof. Steven Krantz, Editor of the Notices, for advice on the style of presentation, and to Prof. V. Vuorinen of Aalto University, Finland, and anonymous reviewers for constructive comments. We thank the generous support from the Qatar National Research Funds grant National Priority Research Project \#5-674-1-114 and Texas A\&M University's internal grant for interdisciplinary research, CRI Scully funds, through the Institute for Quantum Science and Engineering. We also thank the staff at TAMU Supercomputing Facility and TASC at TAMUQ for software support and time allocation. 


\section{References}

[Aba] Abaqus FEA. www.3ds.com/productsservices/simulia

[Abr11] SERGE Abrate, Hull slamming, Applied Mechanics Reviews, 64(6):060803, 2011.

[Bar10] ARNOLD BARNETT, Cross-national differences in aviation safety records, Transportation Science, 44(3):322-332, 2010.

$\left[\mathrm{CXM}^{+} 14\right]$ GoOng CHEN, QINGANG XIOng, PhiliP J. MoRRis, Eric G. PAterson, AleXey SergeeV, and YI-CHING WANG, OpenFOAM for computational fluid dynamics, Notices of the AMS 61 (2014), no.4, 354-363.

[Fab57] ANDREW G. FABULA, Ellipse-fitting approximation of two-dimensional, normal symmetric impact of rigid bodies on water, in Proceedings of the 5th midwestern conference on fluid mechanics, A. M. Kuethe, editor, Ann Arbor; The University of Michigan Press, 1957, pp. 299-315.

[Fin14] DAVID FinkLeman, A mathematical and engineering approach to the search of MH370, 2014, Powerpoint Presentation (unpublished).

[FWR87] EDWIN L. FASANELLA, E WIDMAYER, and MARTHA P. ROBINSON, Structural analysis of the controlled impact demonstration of a jet transport airplane, Journal of Aircraft 24 (1987), no. 4, 274-280.

[Gar53] P. R. GARABEDIAN, Oblique water entry of a wedge, Communications on Pure and Applied Mathematics 6 (1953), no. 2, 157-165.

[GLQW13] BAODONG GUO, PeIQING LIU, QIULIN Qu, and JIAWEN WANG, Effect of pitch angle on initial stage of a transport airplane ditching. Chinese Journal of Aeronautics 26 (2013), no 1, 17-26.

[HN81] CYRIL W HiRT and BILly D Nichols, Volume of fluid (vof) method for the dynamics of free boundaries. Journal of Computational Physics 39 (1981), no. 1, 201-225.

[LQG $\left.{ }^{+} 14\right]$ FEIQING LiU, QIULIN QU, BAODONG GUO, XING JIN, JIALI WU, and KAI ZHANG, Application of computational fluid dynamics in the planned ditching of a transport airplane. Mechanics and Practices, 36 (2014), 278-284. (in Chinese with English abstract).

[lsd] LS-DYNA. www. 1stc. com/products/1s-dyna

[Mac79] A. M. MACKEY, A mathematical model of water entry, Admiralty Underwater Weapons Establishment TN, (636/79), 1979. Publisher listed as PN.

[MHV59] John R McGeheE, Melvin E Hathaway, and VICTOR L VAUGHAN, Water-landing characteristics of a reentry capsule, National Aeronautics and Space Administration, 1959.

[MP93] B. MOHAMMADI and OlIVIER PIRONNEAU, Analysis of the K-epsilon Turbulence Model, Wiley-Masson Series Research in Applied Mathematics, 1994.

[not] Notices of the American Mathematical Society. [ope] OpenFOAM. openfoam.org/

[OS88] STANLEy OSHER and JAMES A SeTHian, Fronts propagating with curvature-dependent speed: Algorithms based on Hamilton-Jacobi formulations, Journal of Computational Physics, 79 (1988), no. 1, 12-49.
[RL14] T. CHACón REBOLLO and ROGER LEWANDOWSKI, Mathematical and Numerical Foundations of Turbulence Models and Applications, Springer, 2014.

[Son03] GIHUN SoN, Efficient implementation of a coupled level-set and volume-of-fluid method for three-dimensional incompressible twophase flows, Numerical Heat Transfer: Part B: Fundamentals, 43 (2003), no. 6, 549-565.

[SS51] M. SHIFFMAN and D. C. SPENCER, The force of impact on a cone striking a water surface (vertical entry), Communications on Pure and Applied Mathematics, 4 (1951), no. 4, 379-417.

[SSO94] MARK SUSSMAN, PETER SMEREKA, and STANLEy OSHER, A level set approach for computing solutions to incompressible two-phase flow, Journal of Computational Physics, 114 (1994), no. 1, 146-159.

[syr] 4 possible ways Malaysia flight 370 hit the water and how each would affect the search, Associated Press, April 8, 2014.

[TNY85] H. TAKEWAKI, A. NiSHIGUCHI, and T. YABE, Cubic interpolated pseudo-particle method (cip) for solving hyperbolic-type equations, Journal of Computational Physics, 61 (1985), no. 2, 261-268.

[23] US Airways Flight 1549. en.wikipedia.org/ wiki/US_Airways_Flight_1549

[vK29] THEODORE VON KÁRMÁN, The impact on seaplane floats during landing, NACA Technical Note No. 321, 1929.

[Wag31] HERBERT WAGNER, Landing of seaplanes, NACA Technical Memorandums, No. 622, 1931.

[WSH04] G. X. WU, H. Sun, and Y. S. HE, Numerical simulation and experimental study of water entry of a wedge in free fall motion, Journal of Fluids and Structures, 19 (2004), no. 3, 277-289.

[WY86a] T. WIERZBICKI and D. K. Yue, Spacecraft crashworthiness-towards reconstruction of the Challenger accident, American Society of Mechanical Engineers, Applied Mechanics Division, $A M D, 79$ (1986), 31-46.

[WY86b] TOMASZ WIERZBICKI and Dick K. YUE, Impact damage of the Challenger crew compartment, Journal of Spacecraft and Rockets, 23 (1986), no. 6, 646-654.

[Zwe14] JoHn ZwECK, How did Inmarsat deduce possible flight paths for MH370? SIAM News, May 1, 2014. 